\title{
Experimental and Theoretical Characterization of Dielectric Barrier Discharge in Mercury Diiodide Vapor, Xenon and Helium Gaseous Mixture
}

\author{
Antonina Malinina, Alexandr Malinin \\ Department of Quantum Electronics, Uzhgorod National University, Uzhgorod, Ukraine
}

Email address:

ant.malinina@yandex.ua (A. Malinina)

To cite this article:

Antonina Malinina, Alexandr Malinin. Experimental and Theoretical Characterization of Dielectric Barrier Discharge in Mercury Diiodide Vapor, Xenon and Helium Gaseous Mixture. American Journal of Optics and Photonics. Vol. 4, No. 2, 2016, pp. 14-19. doi: 10.11648/j.ajop.20160402.11

Received: August 26, 2016; Accepted: September 3, 2016; Published: October 10, 2016

\begin{abstract}
The results of studies of dielectric-barrier discharge (DBD) plasma optical characteristics in mixtures of mercury diiodide vapor, xenon and helium are presented. Regularities in spectral, temporal and energy characteristics of plasma, depending on the partial pressures of the mixture components are established. An average and pulsed radiation power of 0.8 Watts and 293 Watts is reached respectively from the emission volume $111 \cdot 10^{-6} \mathrm{~m}^{3}$ in violet-blue spectral range.
\end{abstract}

Keywords: DBD, Low-temperature Plasma, Parameters, Visible Spectral Range of Radiation, Energy Characteristics, Molecules Vapor, Helium, Xenon

\section{Introduction}

Gas-discharge plasma based on mixtures of inert gases with a small addition of mercury diiodide vapors $\left(\mathrm{HgI}_{2}\right)$ is used in excimer (or exciplex) emitters (lasers and lamps (excilamps)) of violet-blue spectral range [1-5]. These lamps attract the attention of scientists and technologists due to their narrow spectral emission band suitable for intensive illumination of large areas. Violet-blue light of these lamps can be used in scientific researches, photonics, biotechnology, providing plant food astronauts during prolonged stays in space, medicine and in the manufacture of gas-discharge display panels [6 - 9].

The aim of our research was to determine the optical characteristics of the emission in the violet-blue spectral range of dielectric barrier discharge (DBD) plasma and identify regularities that make it possible to increase the output power.

\section{Experimental Setup and Measurement Techniques}

The discharge plasma in mixtures of mercury diiodide vapor with helium and xenon was created in the device of cylindrical design - gas -discharge radiation source (GDRS).
Figure 1 shows the construction of a gas -discharge radiation source. It is made of a quartz tube (1 (quartz glass KU-2)) $0.034 \mathrm{~m}$ in diameter and $0.20 \mathrm{~m}$ long. The electrode (2) of circular section $4 \cdot 10^{-3} \mathrm{~m}$ in diameter made of tungsten is located inside on the axis. The outer electrode (3) is made of metal mesh (stainless steel, transmittance 0.7 ). The heating temperature of the radiator was determined by thermocouple (5). On the opposite surface the capillary was placed (6), $1 \cdot 10^{-3} \mathrm{~m}$ in diameter, which serves to reduce the removal of mercury diiodide vapor from the lamp in pumping system. The working volume (4) was equal to $111 \cdot 10^{-6} \mathrm{~m}^{3}$.

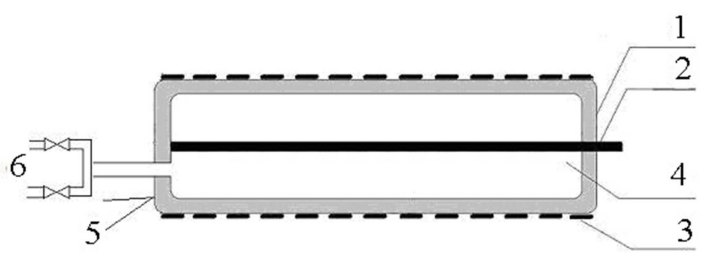

Figure 1. The construction of the gas -discharge radiation source: 1- quartz tube, 2-inner electrode, 3- external (mesh) electrode, 4- discharge zone, 5thermocouple, 6-valves of the pumping system and gas inlet.

Studies of optical characteristics were carried out using the experimental setup, a block schema of which is shown in Figure 2. The main components of the experimental setup 
were: gas -discharge radiation source (GDRS), vacuum pumping system and gas-inlet (VPS), high voltage pulsed power supply (HVPPS) and the registration system of radiation. The registration system included: a monochromator (M) SD-7, a photodetector (PD) photomultiplier FEU-106, or e-linear multiplier 14 ELU-FS, electrical signals amplifier (A) U5-9, data recorder (DR) KSP-4, voltmeter (V) SCH4300, oscilloscope (O) S1-72 and Rogowski coil (RC).

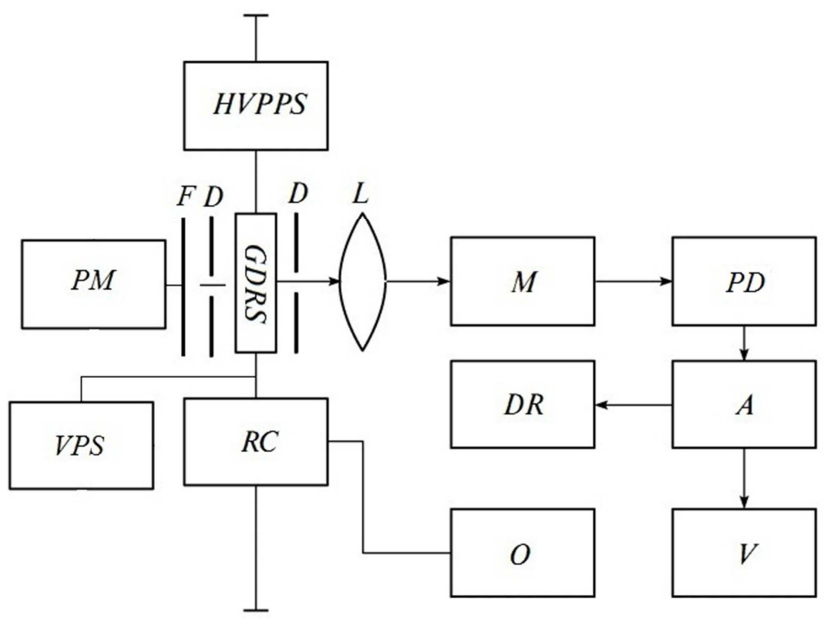

Figure 2. Block schema of the experimental setup: (HVPPS) high voltage pulsed power supply, (GDRS) gas -discharge radiation source, (D) diaphragm, (L) lens, (F) filter, (M) grating monochromator, (PD) photodetector, (A) amplifier, (DR) data recorder, (O) oscilloscope, (RC) Rogowski coil, (V) voltmeter, (PM) power meter, (VPS) vacuum pumping system and gas-inlet.

Excitation of the working mixture in dielectric barrier discharge (DBD) at atmospheric pressure was carried out with the power supply with pulse-periodic form of the output voltage (HVPPS) with the possibility of frequency adjustment in the range $1-20 \mathrm{kHz}$ and the amplitude of the voltage pulses in the range $10-30 \mathrm{kV}$.

Working mixtures have been prepared directly in the bulk of the device. Powder of mercury diiodide $\left(\mathrm{HgI}_{2}\right)$ in an amount of $60 \mathrm{mg}$ was spread uniformly inside the discharge cell. In studies of optical characteristics of gas-discharge plasma radiation the partial vapor pressure of mercury diiodide was created by self-heating of the working mixture by the discharge energy dissipation. After loading the salt dehydration of radiation source was carried out by heating at $50{ }^{\circ} \mathrm{C}$ and pumping during 2 hours. The values of the partial pressure of mercury diiodide saturated vapor were determined by the temperature at the coldest point of the radiator based on the interpolation reference data of [10]. The partial pressures of xenon and helium were measured by exemplary diaphragm vacuum gauge and pressure gauge.

The discharge emission was recorded in the direction perpendicular to the side surface of the gas -discharge radiation source (GDRS). After passing through the diaphragm (D) and the lens (L) it was directed onto the entrance slit of the diffraction monochromator ( $\mathrm{M}$, grating 600 lines. $/ \mathrm{mm}$ ). The emission spectra were recorded in the range $350-800 \mathrm{~nm}$. The spectral resolution of the registration system was $2.4 \mathrm{~nm}$. Calibration of the registration system was carried out using standard tungsten lamp SI 8-200 at filament temperature $\mathrm{T}=2173 \mathrm{~K}$.

Voltage and current pulses of the radiator were recorded with an oscilloscope S1-72, a signal on which was fed from the voltage divider and integrating circuit of the calibrated Rogowski coil.

Amplitude-temporal characteristics of radiation in the range 400-450 nm, allocated with light filter type SZS 8 were determined using linear photomultiplier 14 ELU - FS which signal was recorded by oscilloscope S1-72.

The average power of the radiation source was measured with an instrument "Quartz-01". The optical signal after passing through the diaphragm (D) area $0.25 \mathrm{~cm}^{2}$ incident on the filter (F) SZS 8, after which on the measuring head of the device "Quartz-01". The power radiated by the entire surface of the radiation source, was determined from the expression [11]:

$$
\mathrm{P}_{\text {rad. }}=\Omega_{0} \mathrm{P}_{\mathrm{d}} / \Omega_{\mathrm{d}}
$$

where $P_{d}$ is the power recorded by the radiation detector; $\Omega_{0}$ is the equivalent solid angle (for a cylindrical surface, it is equal to $\pi^{2}$ [19]); and $\Omega_{\mathrm{d}}=\mathrm{S}_{\mathrm{d}} / 1_{0}^{2}$ is the solid angle of the detector, $S_{d}$ the area of the detector window ; $1_{0}$ - the distance from the detector to the radiation source.

Pulse power $\left(\mathrm{P}_{\mathrm{p}}\right)$ was determined on the basis of known average power $\left(\mathrm{P}_{\text {rad. }}\right)$, duration $(\Delta \tau)$ and pulse repetition frequency $(\mathrm{f})$ from the relation:

$$
\mathrm{P}_{\text {rad.. }}=\mathrm{P}_{\mathrm{p} .} \cdot \Delta \tau \cdot \mathrm{f}
$$

\section{Results and Discussion}

\subsection{Experimental Results}

The studies were carried out in mercury diiodide, xenon and helium mixture $\left(\mathrm{HgI}_{2}: \mathrm{Xe}: \mathrm{He}\right)$. Xenon partial pressure was varied in the range $(0-7) \mathrm{kPa}$, and for $\mathrm{HgI}_{2}$ vapor and helium, it was equal to $100 \mathrm{~Pa}$ and $170 \mathrm{~Pa}$, respectively. The partial pressure of mercury diiodide vapor and helium was chosen on the basis of our experimental data for mercury diiodide vapor and helium mixture, such, at which the maximum output power was reached [5].

Immediately after the initiation of atmospheric pressure barrier discharge filamentary mode of DBD burning was observed, set of conical shape microdischarges with vertex on the metal electrode and the base on the inner surface of the quartz tube radiator. Color of the discharge in the initial stage (first 30 seconds) was determined by a helium buffer gas, namely pink color. In the subsequent time the discharge was burning violet-blue colour. Wherein mainly diffuse and uniform nature of the discharge was observed, the number of filaments has decreased dramatically, and their number did not exceed three, visibly brightness contrast was smoothed in the volume discharge (glow along the length of the tube has a uniform character, but in radius - brighter on the surface of 
the inner electrode). The thickness of the discharge region and the discharge length is $0.013 \mathrm{~m}$ and $0.20 \mathrm{~m}$, respectively.

At the pulse repetition frequency $\mathrm{f}=18 \mathrm{kHz}$ and voltage pulses amplitude $23 \mathrm{kV}$ for mercury diiodide vapor, xenon and helium mixture (Figure 3 a) there was the same emission spectrum as in a binary mixture $\left(\mathrm{HgI}_{2}: \mathrm{He}\right)$ [5]. At low repetition rate of the pump pulse $(1000 \mathrm{~Hz})$ with the system spectral bands of mercury monoiodide $\mathrm{B} \rightarrow \mathrm{X}$ transition, xenon line $\lambda=823 \mathrm{~nm}$ is observed, the transition $6 \mathrm{~s}-6 \mathrm{p}$, as well as xenon lines $6 \mathrm{~s}-7 \mathrm{p}(\lambda=462 \mathrm{~nm})$ and $6 \mathrm{~s}-7 \mathrm{p}(\lambda=467$ $\mathrm{nm})$. Transcript of the emission spectra was carried out by reference data of works $[12,13]$.
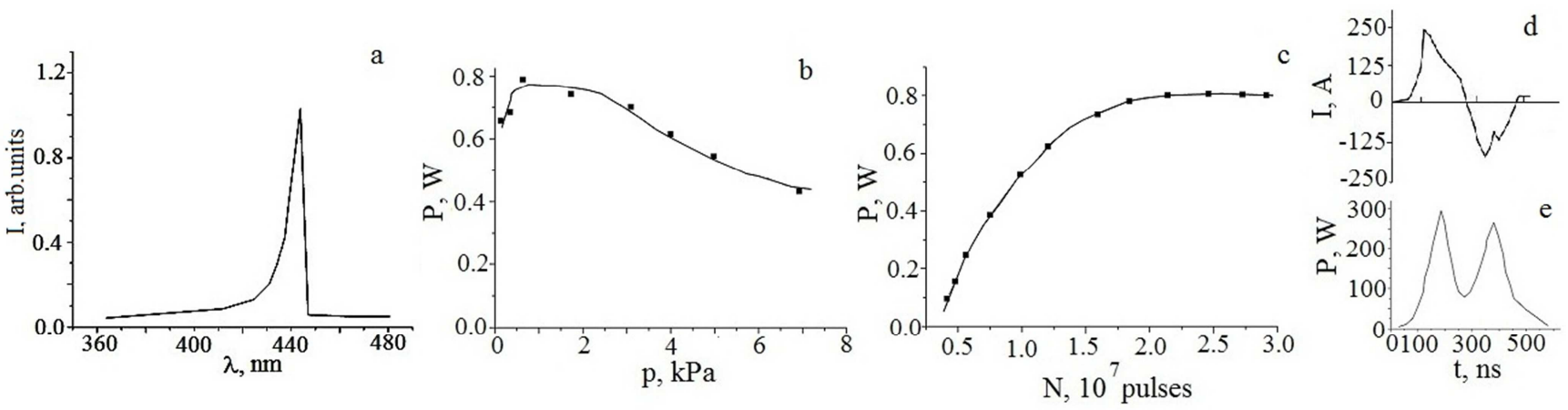

Figure 3. The emission spectrum of a gas discharge plasma in a mixture $\mathrm{HgI}_{2}: \mathrm{Xe}: \mathrm{He}=100 \mathrm{~Pa}: 1 \mathrm{kPa}: 170 \mathrm{kPa}$ (a). The dependence of the mean radiation power of exciplex $\mathrm{HgI}^{*}$ on the partial pressures of xenon (b). The dependence of the average radiation power of exciplex HgI* on the total number of the pump pulses (c). Oscillograms: current pulses of the discharge and radiated power respectively (d, e). The amplitude of the voltage pulses and the repetition frequency is equal to $23 \mathrm{kV}$ and $18 \mathrm{kHz}$ respectively.

The results of studies of the dependence of the average power of radiation on the partial pressures of xenon, as well as the operation time of the radiation source are presented in Figure $3(\mathrm{~b}, \mathrm{c})$. In mixture $\mathrm{HgI}_{2}: \mathrm{Xe}: \mathrm{He}$ the maximum radiated power has a higher value 0.8 Watts at the partial vapor pressures of mercury diiodide, xenon and helium 100 $\mathrm{Pa}, 1 \mathrm{kPa}$ and $170 \mathrm{kPa}$, respectively, that is on $33 \%$ higher than for a mixture of mercury diiodide vapor and helium [5]. A characteristic regularity, namely the radiation power increase with increasing partial pressures of xenon, reaching the maximum and subsequently it's decrease with an increase of partial pressures is observed (Figure $3 b$ ).

For the dependence of the radiation power on the number of pumping pulses (Figure 3 (c) is characteristic that for a mixture of diiodide vapor, xenon and helium a maximum value was observed before in time than for the mixture diiodide vapor with helium [5].

Waveforms: discharge current pulses and output power are shown in Figure 3 d, e. Current pulses are of different polarity. Their amplitude and duration have the same values as in the binary mixture [5]. Their form is caused by recharge circuit "dielectric-plasma". The pulses of radiation are of the same polarity (Figure 3 e). Pulse duration was 120 ns. Accuracy and reproducibility of the measurement results did not differ from the values of a binary mixture $\left(\mathrm{HgI}_{2}: \mathrm{He}\right)$ and were equal to $10 \%$ and $90 \%$, respectively.

\subsection{Calculation of Some Plasma Parameters}

To determine the parameters numerical modeling technique was used that is described in [5]. For numerical calculations the ratio of the components $\mathrm{HgI}_{2}-\mathrm{Xe}-\mathrm{He}=$ $0.04 \%-0.58 \%-99.38 \%$ was used at which the maximum power was observed in our experiment at a total pressure of a mixture $171.1 \mathrm{kPa}$.

In the collision integral of electrons with atoms of helium, xenon and mercury diiodide molecules were taken into account the following processes: elastic scattering, excitation of energy levels of the atom helium $\left(2^{3} \mathrm{~S}, 2^{1} \mathrm{~S}, 2^{3} \mathrm{P}, 2^{1} \mathrm{P}, 3 \mathrm{SPD}\right.$, 4SPD, 5SPD), ionization of helium atom; elastic scattering and excitation of the electronic states of xenon atom with a threshold energies: $3.4 \mathrm{eV}, 8.31 \mathrm{eV}, 8.44 \mathrm{eV}, 9.69 \mathrm{eV}, 10.0$ $\mathrm{eV}, 11.0 \mathrm{eV}, 11.7 \mathrm{eV}$, the ionization of xenon atoms and ionization of mercury diiodide molecules, dissociative excitation of electronic $\mathrm{B}^{2} \Sigma{ }_{1 / 2}^{+}$- state of mercury monoiodide. Data on the absolute values of the effective cross sections of these processes and their dependences on the electrons energy are taken from the database [14-16].

The electron density $\mathrm{N}_{\mathrm{e}}$ was calculated by the relation [26]:

$$
\mathrm{N}_{\mathrm{e}}=\mathrm{J} / \mathrm{e} \mathrm{V}_{\mathrm{dr}}
$$

where, $\mathrm{j}$ is the discharge current density; e is the charge of an electron; and $V_{\mathrm{dr}}$ is the electron drift velocity,

Electron drift velocity was determined from the expression [17]:

$$
\mathrm{V}_{\mathrm{dr}}=\mu_{\mathrm{e}} \mathrm{E} \text {, }
$$

where $\mu_{\mathrm{e}}$ is the electron mobility and $\mathrm{E}$ is the electric field on plasma.

The electric field on plasma was calculated according to the formula:

$$
\mathrm{E}=\mathrm{U}_{\mathrm{pl} .} / \mathrm{d},
$$

with $\mathrm{U}_{\mathrm{pl}}$ - voltage across plasma, d-discharge gap.

The voltage on plasma $\left(\mathrm{U}_{\mathrm{pl}}\right)$ was determined by Kirchhoff's second rule, using the experimentally measured values of the time variation of the voltage that is applied to the electrodes of the gas discharge radiation source (U) and also the voltage drop across the capacitance of the dielectric $\left(\mathrm{U}_{\mathrm{dl}}\right)$ : 


$$
\mathrm{U}_{\mathrm{pl} .}=\mathrm{U}-\mathrm{U}_{\mathrm{dl} .},
$$

Voltage $\left(\mathrm{U}_{\mathrm{dl}}\right)$ calculated by the displaced charge $(\mathrm{Q})$ and the capacitance of the dielectric barrier $\left(\mathrm{C}_{\mathrm{d}}\right)$ :

$$
\mathrm{U}_{\mathrm{dl} .}=\mathrm{Q} / \mathrm{C}_{\mathrm{d}}
$$

Moved charge in the chain is determined by integrating the current based on the initial conditions:

$$
\mathrm{Q}(\mathrm{t})=\int_{0}^{t} I(t) d t+\mathrm{Q}_{0},
$$
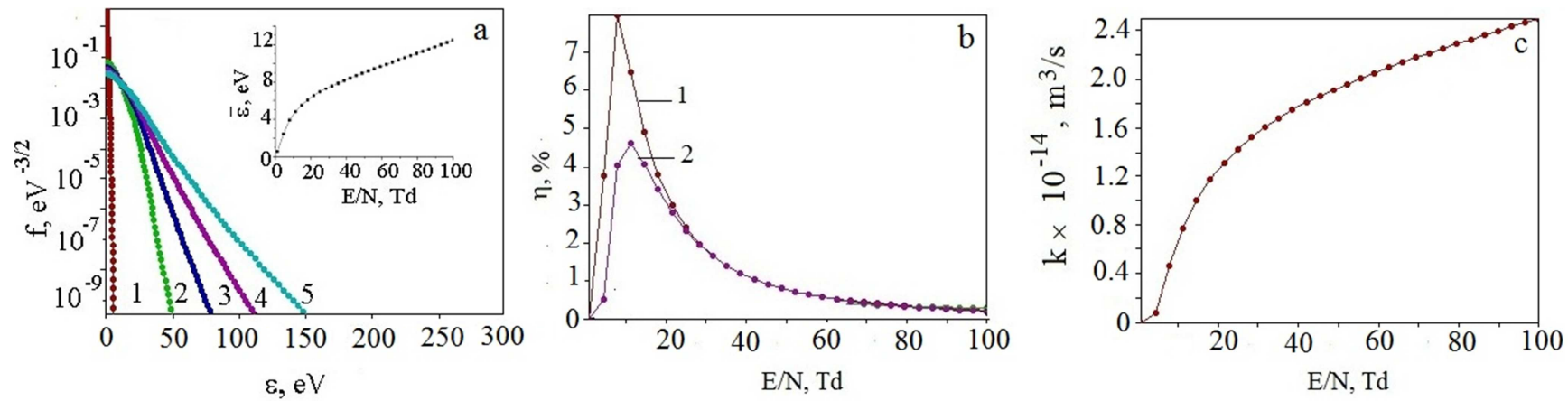

Figure 4. Plasma EEDF in a mixture HgJ - Xe - He for E/N parameter values: 1 (1), 25.8 (2) 50.5 (3) 75.3 (4), 100 (5) Td; the inset- dependence of the mean electron energy on parameter E/N (a). Dependences of discharge power specific losses on the parameter E/N: on dissociative excitation of $B^{2} \Sigma^{+}{ }_{1 / 2}-$ state of mercury monoiodide molecules by electrons $(b, 1)$, on ${ }^{3} P_{2}$ - state excitation of xenon atoms by electrons $(b, 2)$ and rate constants of dissociative excitation of mercury monoiodide molecules $B^{2} \Sigma_{1 / 2}^{+}$-state by electrons on the parameter $E / N(c)$. The total mixture pressure $P=171.1 \mathrm{kPa}$.

The results of numerical calculation of mean electron energies allow to define their temperature in the gas discharge plasma of the radiator from the well-known relation [26]:

$$
\varepsilon=3 / 2 \mathrm{kT}
$$

where $\varepsilon$ - electron energy, k-Boltzmann's constant, Ttemperature in degrees Kelvin.

It increases from $6728 \mathrm{~K}$ to $144884 \mathrm{~K}$ when the parameter E/ $\mathrm{N}$ changes from 1 to $100 \mathrm{Td}$ respectively.

The electron mobility, as follows from the results of numerical calculations for mercury diiodide vapor, xenon and helium varies in the range $(5.2-2.3) \times 10^{24} \mathrm{~N}^{-1}\left(\mathrm{~m} \mathrm{~V} \mathrm{~s}^{)-1}\right.$ as the parameter $\mathrm{E} / \mathrm{N}$ varies in the range $1-100 \mathrm{Td}$, which gives the value of the electrons drift velocity $3.1 \cdot 10^{6} \mathrm{~m} / \mathrm{s}$ and $1.36 \cdot 10^{6} \mathrm{~m} / \mathrm{s}$, respectively, at a field strength on plasma $17.2 \cdot 10^{6} \mathrm{~V} / \mathrm{m}$ and the value of the electron concentration $1.3 \cdot 10^{18} \mathrm{~m}^{-3}-4.6 \cdot 10^{18} \mathrm{~m}^{-3}$ for current density $100 \cdot 10^{4} \mathrm{~A} /$ $\mathrm{m}^{2}$ at the surface of the inner electrode of radiation sources $\left(2.5 \cdot 10^{-4} \mathrm{~m}^{2}\right)$.

Specific losses of discharge power for the dissociative excitation of mercury monoiodide molecules (state $\mathrm{B}^{2} \Sigma^{+}{ }_{1 / 2}$ ) (Figure $4 \mathrm{~b}$, curve 1) increase with the parameter $\mathrm{E} / \mathrm{N}$, reach a maximum of $8 \%$ for $\mathrm{E} / \mathrm{N}=7.8 \mathrm{Td}$, and under a further increase of the parameter $\mathrm{E} / \mathrm{N}$ decrease and reach a value of $0.23 \%$ for the parameter $\mathrm{E} / \mathrm{N}=100 \mathrm{Td}$. Specific losses of discharge power for process of excitation of the metastable state ${ }^{3} \mathrm{P}_{2}$ of xenon atoms (Figure $4 \mathrm{~b}$, curve 2 ) have a similar dependence on the reduced electric field strength, reach a maximum $4.7 \%$, for the $\mathrm{E} / \mathrm{N}=11.2 \mathrm{Td}$. The rate of increase and fall of specific losses of discharge power on this process and its value are linked to the nature of the dependence of the effective cross section of $\mathrm{B}^{2} \Sigma^{+}{ }_{1 / 2}$ state excitation and ${ }^{3} \mathrm{P}_{2}$ states excitation of xenon atoms on the electron energy, its absolute value, the dependence of the electron energy distribution function on the values of the parameter $\mathrm{E} / \mathrm{N}$ [17].

The dependence of the rate constants of dissociative excitation of mercury monoiodide molecules by electrons (Figure $4 \mathrm{c}$ ) on reduced electric field strength is comparable with the same dependence for the binary mixture. And in the range of values of the parameter $\mathrm{E} / \mathrm{N}=25-75 \mathrm{Td}$, in which operates a radiation source, a rate constant of excitation of mercury monoiodide molecules $\mathrm{B}^{2} \Sigma^{+}{ }_{1 / 2}$ - state has smaller magnitudes [5]. Its value is in the range $(1.4-2.2) 10^{-14} \mathrm{~m}^{3} / \mathrm{s}$.

The emergence of emission from electronic-vibrational transition $\mathrm{B}^{2} \Sigma_{1 / 2}^{+} \rightarrow \mathrm{X}^{2} \Sigma^{+}{ }_{1 / 2}$ of $\mathrm{HgI}{ }^{*}$ exciplex molecules in a gas-discharge plasma on three-component mixtures of mercury diiodide, xenon and helium occurs in consequence of the same process as for the binary mixture, except quenching process of mercury monoiodide molecules state by xenon atoms $[15,18,19]$ :

$$
\begin{gathered}
\mathrm{HgI}_{2}+\mathrm{e} \rightarrow \mathrm{HgJ}_{2} * \rightarrow \mathrm{HgJ}^{*}+\left\{\begin{array}{l}
\left.\mathrm{I}^{2} P_{3 / 2}\right)+e, \\
\mathrm{I}^{-} .
\end{array}\right. \\
\mathrm{HgI} * \mathrm{HgI}+\mathrm{h} v, \\
\mathrm{HgI}^{*}+\mathrm{M} \rightarrow \mathrm{HgI}+\mathrm{M}+\Delta \mathrm{E},
\end{gathered}
$$


where $\mathrm{M}$ - concentration of molecules and atoms $\left(\mathrm{HgI}_{2}, \mathrm{Xe}\right.$, $\mathrm{He}$ ), respectively, $\Delta \mathrm{E}$ - the energy difference in the reaction.

The kinetic equation for the population of the state $\operatorname{HgI}\left(\mathrm{B}^{2} \Sigma_{1 / 2}^{+}\right.$-state):

$$
\frac{d[H g I *]}{d t}=\mathrm{k}_{\mathrm{d}}\left[\mathrm{HgI}_{2}\right]\left[\mathrm{N}_{\mathrm{e}}\right]-\tau_{\mathrm{r}}^{-1}\left[\mathrm{HgI}^{*}\right]-\mathrm{k}_{\mathrm{q}}\left[\mathrm{HgI}^{*}\right][\mathrm{M}],
$$

where $k_{d}$ - rate constant of dissociative excitation of molecules $\mathrm{HgI}^{*}$ by electron impact, $\tau_{\mathrm{r}}$-radiative life time of HgI* molecules $\left(\mathrm{B}^{2} \Sigma_{1 / 2}^{+}\right.$-state $), \mathrm{k}_{\mathrm{q}-}$ quenching rate constant of $\mathrm{HgI}^{*}$ molecules $\left(\mathrm{B}^{2} \Sigma_{1 / 2}^{+}\right.$-state); [HgI*], $\left[\mathrm{HgI}_{2}\right],[\mathrm{Ne}],[\mathrm{M}]$ - concentrations of molecules $\mathrm{HgI}^{*}, \mathrm{HgI}_{2}$, electrons and quenching molecules and atoms $\left(\mathrm{HgI}_{2}, \mathrm{Xe}, \mathrm{He}\right)$ respectively.

For quasi-stationary case from the relation (4) the emission intensity:

$$
I_{H g I^{*}}^{-1}=\alpha\left(1+\mathrm{k}_{\mathrm{q}} \tau_{\mathrm{r}}[\mathrm{M}]\right)
$$

where $\alpha=\left(\mathrm{k}_{\mathrm{d}} \mathrm{hv}\left[\mathrm{HgI}_{2}\right]\left[\mathrm{N}_{\mathrm{e}}\right]\right)^{-1}$.

The dependence of the emission intensity on the wavelength (Figure 3 a), explained by the same laws, which are inherent to the binary mixture due to the fact that concentrations of mercury diiodide molecules and helium in both mixtures are identical $[5,12,20,21]$.

The dependence of the radiation power of exciplex molecule $\mathrm{HgI}^{*}$ on the partial pressure of xenon (Figure $3 \mathrm{~b}$ ) is caused primarily by the following processes: an increase in the electron concentration with increasing of xenon partial pressure in mixtures, changes the fraction of discharge energy, which is consumed for working mixture heating; a change in the mean electron energy and the rate constant of exciplex molecules $\mathrm{HgI}^{*}$ excitation depending on the values of the parameter $\mathrm{E} / \mathrm{N}$, as well as the process of quenching of $\mathrm{HgI}^{*}$ molecules $\mathrm{B}^{2} \Sigma_{1 / 2}^{+}-$state in collisions with xenon atoms $[17,22]$. The presence of a maximum and a further drop in the radiation power of mercury monoiodide exciplex molecules with an increase of partial pressure of xenon is due to the process of quenching this state of mercury monoiodide molecules in collisions with atoms of xenon, the rate constant of which is equal to $2.210^{-19} \mathrm{~m}^{3} / \mathrm{s}$, respectively [23]:

$$
\mathrm{HgI}^{*}+\mathrm{Xe} \rightarrow \mathrm{HgI}+\mathrm{Xe}+\Delta \mathrm{E},
$$

where $\Delta \mathrm{E}$ - the energy difference in the reaction.

Achieving the maximum value of the radiation power in mercury diiodide vapor, xenon, and helium mixture earlier in time (Figure $3 \mathrm{c}$ ) than with a mixture of mercury diiodide vapor and helium (Figure $1 \mathrm{~d}[5]$ ) is caused by the additional channel of elastic scattering of electrons by atoms of xenon, which leads to a greater heating rate of the mixture and respectively, to increase the partial pressure of mercury diiodide vapor and ultimately population of $\mathrm{HgI}^{*}$ molecules $\mathrm{B}^{2} \Sigma^{+}{ }_{1 / 2}-$ state.
In mixtures of mercury diiodide vapor with xenon and helium average output power of mercury monoiodide exciplex molecules is higher (Figure $3 \mathrm{~b}, \mathrm{c}$ ), comparable with a mixture of only mercury diiodide vapor and helium (Figure $1 \mathrm{~b}, \mathrm{c}$ [5]) despite the fact that specific power of the discharge on dissociative excitation of $\mathrm{HgI}^{*}$ molecules $\mathrm{B}^{2} \Sigma_{1 / 2}^{+}$-state by electrons is lower (Process 1, Figure $4 \mathrm{~b}$, curve 1 ) than in a mixture of mercury diiodide vapor with helium (Figure $2 \mathrm{~b}$ [5]).

The increase of the radiation power in mercury diiodide vapor, xenon and helium mixture (Figure $3 \mathrm{~b}$, c) comparing with mercury diodide vapor and helium mixture can be caused by the process of quenching mercury monoiodide molecules $\mathrm{C}^{2} \Pi^{+}{ }_{1 / 2}$ and $\mathrm{D}^{2} \Pi^{+}{ }_{3 / 2}$-states by xenon atoms with the transfer of the population to $\mathrm{B}^{2} \Sigma_{1 / 2}^{+}$-state:

$$
\operatorname{HgI}\left(\mathrm{C}^{2} \Pi_{1 / 2}, \mathrm{D}^{2} \Pi_{3 / 2}^{+}\right)+\mathrm{Xe} \rightarrow \operatorname{HgI}\left(\mathrm{B}^{2} \Sigma^{+}{ }_{1 / 2}\right)+\mathrm{Xe}+\Delta \mathrm{E}_{1,2}
$$

which was first discovered in experiments on the photodissociation of mercury diiodide $[22,24]\left(\Delta \mathrm{E}_{1,2}\right.$ - the energy difference between the states $C^{2} \Pi_{1 / 2}, D^{2} \Pi_{3 / 2}$ and $B^{2}$ $\Sigma_{1 / 2}^{+}$molecules HgI). Arguments in favor of this are the change of the ratio of amplitudes of radiation pulses and the reduction of their duration (Figure $3 \mathrm{~d}$ ) in a mixture $\mathrm{HgI}_{2}-\mathrm{Xe}$ He comparable with $\mathrm{HgI}_{2}-\mathrm{He}$ mixture (Figure $1 \mathrm{f}[5]$ ), as well as data on $\mathrm{k}_{\mathrm{q}} \tau=4.5 \cdot 10^{-24} \mathrm{~m}^{3}[23]\left(\mathrm{k}_{\mathrm{q}}\right.$ - quenching rate constant of mercury monoiodide molecules $\mathrm{C}$-state by xenon, $\tau$ lifetime of molecules $\operatorname{HgI}\left(C^{2} \Pi_{1 / 2}\right)$. This quenching process is additional to the main process (1) dissosiative excitation of $\operatorname{HgI}\left(\mathrm{B}^{2} \Sigma_{1 / 2}^{+}\right)$molecules by electrons.

Since the power density of the discharge on the excitation of the metastable state ${ }^{3} \mathrm{P}_{2}$ of xenon atoms has a high value (Figure $4 \mathrm{~b}$, curve 2), the increased value of the radiation power contributes to the collision of metastable xenon atoms $\left({ }^{3} \mathrm{P}_{2}\right.$ - state) with mercury diiodide molecules:

$$
\mathrm{HgI}_{2}+\mathrm{Xe}\left({ }^{3} \mathrm{P}_{2}\right) \rightarrow \mathrm{HgI}_{2} * \rightarrow \operatorname{HgI}\left(C^{2} \Pi_{1 / 2}, \mathrm{D}^{2} \Pi_{3 / 2}^{+}\right)+\mathrm{Xe},(8)
$$

whereby $\mathrm{C}^{2} \Pi^{+}{ }_{1 / 2}$ and $\mathrm{D}^{2} \Pi^{+}{ }_{3 / 2}$-states of mercury monoiodide molecules further populated due to dissociation of the excited state of mercury diiodide molecules, which results in accordance with the process of quenching (8) to a higher population of mercury monoiodide molecules $\mathrm{B}^{2} \Sigma_{1 / 2}^{+}$-state and ultimately to a greater radiation power.

\section{Conclusion}

In conclusion, the experimental and theoretical characteristics of gas-discharge plasma in mercury diiodide vapor, xenon and helium mixture are studied. Regularities in spectral, temporal and energy characteristics of plasma, depending on the partial pressures of the mixture components are established. The values of the partial pressures of mixture components are defined at which the average and pulse power of 0.8 Watts and 293 Watts is reached respectively 
from emission volume $111 \cdot 10^{-6} \mathrm{~m}^{3}$ in violet-blue spectral range. Increased output power can be caused by the process of quenching $\mathrm{C}^{2} \Pi_{1 / 2}^{+}$and $\mathrm{D}^{2} \Pi_{3 / 2}^{+}$states of mercury monoiodide molecules by xenon atoms with the transfer of the population to $\mathrm{B}^{2} \Sigma^{+}{ }_{1 / 2}$-state, as well as the process of collision of a metastable xenon atoms $\left({ }^{3} \mathrm{P}_{2}\right.$ - state ) with mercury diiodide molecules.

Atmospheric pressure barrier discharge plasma in mercury diiodide vapor, xenon and helium mixture can be applied as the working medium of the exciplex radiator in the blue violet spectral range that can be used in scientific researches in biotechnology, photonics, medicine, as well as to create a discharge indicator panels.

\section{References}

[1] Burnham R. Discharge Pumped Mercuric Halide Dissociation Lasers. Applied Physics Letters. Vol. No. 25, 1978, pp. 152156.

[2] Gavrilova Yu E, Zrodnikov V S, Klenentov A D and Podsosonnyi, A S. Excimer $\mathrm{HgJ}^{*}$ Laser Excited by an Electric Discharge. Quant. Electron. Vol. No. 7, 1980, pp. 2495-2497.

[3] Konoplev A N, Kelman V A and Shevera V S. Investigation into Pulse Discharge Emission in $\mathrm{ZnI} 2, \mathrm{CdI}_{2}$ and $\mathrm{HgI}_{2}$ Mixtures with Helium and Neon. Journal of Applied Spectroscopy. Vol. No. 39, 1983, pp. 315-317.

[4] Malinin A.N. Excitation of Mercury Monohalides in the Plasma of Pulse-Periodic Discharge in Mixtures of Mercury Dihalides and Rare Gases. Laser Physics. Vol. No. 7, 1997, pp. $1032-1040$.

[5] Malinina Antonina. Diagnostics of Optical Characteristics and Parameters of Gas-Discharge Plasma Based on Mercury Diiodide and Helium Mixture. Open Journal of Applied Sciences. Vol. No. 5, 2015, pp. 826-832.

[6] Posudin Yu I 1989 Laser Photobiology (Kiev: Vishcha shkola)

[7] Romanenko V D, Krot Yu G, Sirenko L A and Solomatina V D 1999 Biotechnology of Hidrobion Cultivation (Kiev: Institute of Hydrobiology NAS Ukraine).

[8] http://www.nasa.gov/mission_pages/station/research/news/wkl ysumm_week_of_14dec15.html.

[9] Kogelschatz U. Excimer lamps: history, discharge physics and industrial applications. Proc. SPIE. Vol. No.5483, 2004, pp. 272-286.
[10] Efimov A I, Belorukova L P, Vasil'kova I V, and Chechev V P 1983 Properties of Inorganic Compounds:Handbook (Leningrad: Khimiya).

[11] Sapozhnikov R A Theoretical Photometry 1977 (Moscow: Énergiya).

[12] Pearse R W and Gaydon A G 1963 The Identification of Molecular Spectra (New York: Wiley).

[13] Zaidel' A N, Prokof'ev V K, Raiskii S M, Slavnyi V A and Shreider E Ya 1977 Tables of Spectral Lines (Nauka: Moscow).

[14] http://www.bolsig.laplace.univ-tlse.fr/

[15] Kushawaha $\mathrm{V}$ and Mahmood $\mathrm{M}$ J. Electron Impact Dissociation of $\mathrm{HgX}_{2}(\mathrm{X}=\mathrm{Cl}, \mathrm{Br}, \mathrm{I})$. Appl. Phys. Vol. No. 62, 1987, pp. 2173- 2177.

[16] Malinin A N. Excitation of the $\mathrm{B}^{2} \Sigma^{+}{ }_{1 / 2}$ State of Mercury Monohalides by Electron Impact. Laser Phys .Vol. No.7, 1997, pp. 1168-1176.

[17] Raizer Yu P 1991 Gas Discharge Physics (Moscow: Nauka).

[18] Malinin A N. The Efficiency of the Quenching of the $\mathrm{B}^{2} \Sigma_{1 / 2}^{+}$ State in Mercury Monohalides by Halogen-Containing Molecules in Active Media of $\mathrm{HgCl}, \mathrm{HgBr}$ and $\mathrm{HgJ}$ Eximer Lasers. Laser Physics. Vol. No. 7, No. 6, 1997, pp. 1177-1181.

[19] Malinin A N, Shuaibov A K and Shevera V S. Dissociative excitation of the $\mathrm{B}^{2} \Sigma^{+}{ }_{1 / 2}$ states of mercury monohalides by electron impact. Soviet Journal of Quantum Electronics.Vol. No. 13, 1983, pp. 977-978.

[20] Wadt W R. The electronic structure of $\mathrm{HgCl}$ and $\mathrm{HgBr}$, Appl. Phys.Lett. Vol. No. 34, 1979, pp.658-660.

[21] Datsyuk V V, Izmailov I A and Kochelap V A. Vibrational relaxation of excimers. Phys. Usp. Vol. No. 41, 1998, pp. 379 -402 .

[22] Roxlo $\mathrm{C}$ and Mandl A. Quenching Kinetics for the $\mathrm{HgBr}^{*}$ $\left(\mathrm{B}^{2} \Sigma_{1 / 2}\right)$ and $\mathrm{HgJ}^{*}\left(\mathrm{~B}^{2} \Sigma_{1 / 2}, \mathrm{C}^{2} \Pi_{1 / 2}\right)$ States J. Chem. Phys. Vol. No. 72, 1980, pp.541-543.

[23] Iden J G and Waynant R W. HgBr and HgJ B-State Quenching Rate Constans. Appl. Phys. Lett. Vol. No. 34, 1979, pp. 324326.

[24] Bazhulin S P, Basov N G, Bugrimov S N and et al. Blue-violet $\mathrm{HgI} / \mathrm{HgI}_{2}$ laser with wide-band optical pumping by a linearly stabilized surface discharge. Soviet Journal of Quantum Electronics. Vol. No. 16, No. 5, 1986, pp. 663-665. 